\title{
Social dimensions of communication; communicational dimensions of social processes. Some propositions on research lines and problematic
}

ABSTRACT

This paper has the purpose to present theoretical propositions as well as possible research topics and problems over the relations between social practices and communicative practices. Two fundamental hypothesis are sustained: a) the construction of theory and research over communication processes are consolidated the more they are associated with effective propositions over social processes. B) The second hypothesis sustains that it is possible to construct certain analytical categories that can be common and applicable both to social processes as well as specifically communicative, discursive and mediatic ones

\section{KEY WORDS}

categories of analysis

sociocommunicational concepts

life world

\section{RESUMO}

Este artigo tem o propósito de apresentar proposições teóricas, bem como temas de investigação possível e problemas sobre as relações entre práticas sociais e práticas comunicativas. Duas hipóteses são sustentadas fundamentais: a) a construção de teoria e pesquisa sobre os processos de comunicação são consolidados, mais elas estão associadas a proposições efetivo sobre os processos sociais. B) A segunda hipótese sustenta que é possível a construção de determinadas categorias de análise que pode ser comum e aplicável tanto aos processos sociais, bem como especificamente comunicativa, discursiva e midiática queridos.

\section{PALAVRAS-CHAVE}

categorias de análise

conceitos sociocomunicacionais

mundo da vida

\section{Eduardo Andrés Vizer}

Professor da Universidade de Buenos Aires UBA/BA/AR

eavizer@gmail.com
There is no science of discourse considered in itself or by itself: formal proprieties of works reveal their meaning only when referred to social conditions of its production - that is, the positions occupied by their authors in the field of production - or, by the other hand, to the market for which they where produced (which is no other than the own field of production) and eventually to the successive markets of reception of those works (Bourdieu, 1996, p. 129).

Communication: the construction of life worlds? According to the first hypothesis, the field of communication will develop more solidly the more it associates problematic of social action, to the formation of meaning. We can assume the proposition of L. Braga (2004) about the fecundity of investigating problems that rise in the interphases with problems presented by other disciplinary fields or by the own communicational filed in relation to other ones. If this is so - and that is what I pretend to demonstrate -, the first hypothesis over the necessity of developing theoretical and methodological strategies of analysis that associate firmly the research of social processes jointly with communicational ones will be strongly corroborated.

I propose certain innovative propositions related to the theory of "social construction of reality", as a founding process through which human beings phenomenological perceive, categorize, organize, inscribe and adjudicate meanings and values (Vizer, 2003, 2006) to their perceptions, their actions and experiences in social life.

The hypothesis over communication as social construction of reality, tends to be, accepted and repeated practically as an unquestioned dogma. But it hasn't been done enough to develop it in empiric research that could contribute positive knowledge of incredibly complex mechanisms and devices implied in the social processes of "construction of reality". What do we understand by "construction"? How do we define "social" from a "communicational approach"? What do we understand by both "communication" and "reality"? How do their interrelations operate beyond the fact of both being linguistic constructs?

The necessity of proposing associations between individual and collective "experiences" is evident. Between social, cultural, semiotic and even physical mechanisms and actions that participate in the coconstruction of a shared world of common experiences 
that allow human beings to perceive, to hear, to interact and understand how we construct - consciously or not - our shared social contexts and our "life worlds".

I present here some categories of analysis over what we can designate as construction - and sociocultural classification - of different classes of "topologies" implicit in social experiences. I intend to demonstrate that occidental modernity imposed - culturally and ideologically - these categories as universal. They secure criteria for the construction and organization of "meaning" - and an underlying "common sense" - as well as adequate evaluation over the "modes" in which we should perceive and understand the experiences of the "real world". If we accept that communication deals fundamentally with processes of construction of meaning, we can sustain that it studies the processes through which - in this historic moment - individuals, communities and cultures construct and adjudicate meanings and values to their experiences - whether personal or collective - towards nature and the physical world, social relations and bonds; toward symbols and cultural forms, in relation to individuals and their personal worlds, their religions and transcendental searches for values and meanings of life.

If we accept that some shared categories of attribution of meaning have been generalized and are being shared by different societies, this categories would allow us to find a strong foundation for developing communication studies associated with experiences over social practices, cultural processes, language or mass media, and therefore with the theory of "social construction of reality".

I intend to demonstrate that certain categories of attribution of meaning to reality and shared social contexts, will allow to analyze both language and everyday life, audiovisual media and arts based in images (such as painting and photography). If the general hypothesis sustained at the beginning is exact (that research over communication processes should be related to social ones) the propositions and categories of analysis should - at least in theory - be valid to deepen both: social studies as well as communications. Language, as well as other symbolic systems should also manifest - or express - some basic dimensions of social experience that I will present in this paper. Semiolinguistic processes would generate the formation of symbolic devices that would allow individuals to realize transformations and linguistic exchanges that assure the creation of shared rules between social agents participating in the "coconstruction and cultivation" of realities through communication (so as the descriptive and performative functions in language).

I propose a three dimensional model of communication processes (Vizer, 1983). 1) A referential dimension, (construction of "objects" through the communication process, whether linguistic, imagistic, technological, informational or else). 2) Interfererential dimension (through which human beings "refer and construct" themselves one another mutually as agents in a shared context, differing from the positivistic concept of "interaction"). 3) Auto-referential dimension (a "function" of "social construction of the self", the presentation of the self as an "identity" with individual marks and characteristics that allow differentiation and individuation).

I depart from a general proposition: it is strategic to study "communicative and meaning processes as relations that are constructed by forms of symbolic appropriation of the world" (as a "strategic cultivation" of social reality). Individuals (as well as groups and institutions) appropriate and cultivate their physical, their social and cultural ecologies through objectivation (referentiation), mutual recognition as meaningful subjects (intereferentiation), and as differentiated selves with an identity (self-referentiation).

Information and cultural processes are conceived as communicational objects and devices (languages, images, symbols, social rules) to which humans resort for "resources" to construct and cultivate foreseeable relations and situations in different contexts and domains of reality conceived as "topological ecologies". Relations with the physical world are perceived holistically, mediated by the senses of our own body; relations with a "social ecology" (sense of belonging and identification with social collectives: culture, country, ethnicity, etc.). Then relations with an emotional ecology: family, friends, community, religion, etc. A symbolic ecology of cultural forms and expressions: forms, architecture, art, communicative codes, etc. Finally, we must consider the exponential and intrusive applications of technology, as an expression of modern "technological culture", which actually can construct from biotechnological "ecologies" to completely artificial ones (as in spaceships), up to virtual reality ecologies.

Humans appropriate themselves and "cultivate" their close environment (from the minimal personal spaces, to our gardens and architecture). We can consider at least two kinds of control of the environment. a) A "technical and operative control" over the devices that regulate natural and physical contexts of our everyday life, and sociotechnical mechanisms and devices which regulate conditions for the reproduction and adaptation of the environment. And we need a second kind of control: b) "symbolic control processes": such as reflexivity, acknowledgement, recognition, interpretation and construction of meaning and values over situations and realities. A symbolic topos (real or imaginary) which assure us our feet and our minds are grounded in a shared "principle of reality".

Cultural objects and devices (such as language, images, art) could be considered "informational resources" (or resources of and for information 
processing and appropriation). And communication as the "setting in action" of the former as expressive resources by the social actors, in order to (re)construct meaningfully their different environments. The "setting in action" can be considered as the original source of learning of life experiences by human beings. Socialization is precisely the reflexive and dynamic fixation of these experiences of action and meaning in the memory, and a process of articulation between perception and the acknowledgment of the adequate responses according to expected relations with the material, the social and symbolic ethos of a culture. I believe it is almost obvious to consider socialization as the construction of experiences of "cultivation devices" through which men and women intend to assure the control of - and some level of "power" over - their personal lifeworlds.

Communication can be considered the concrete and objective expression of the permanent process of reconstruction of the different "contexts of reality" we build and cultivate in everyday life. We "cultivate our individual realities" as precious gardens, or as a workshop filled with the instruments we use as resources for the reconstruction of our lifeworlds, of our "physical, social, cultural and imaginary ecologies". I consider social communication as the symbolic and meaningful action through which society constructs culturally its "social ecologies". An environmental cultivation, a milieu which individuals and communities can generate (consciously or unconsciously) through different forms of learning and toil, producing the necessary resources for the social collective. Social agents put themselves in "inaction" through the culturally learned devices that are permanently reproduced. This implies work: structuring space and time; physical, social, symbolic and even imaginary forms of work and toil. Societies regenerate their productive resources constructing complex devices for organized social practices. These practices are institutionalized as structures of a system in order to occupy and develop the multiple spaces and times which assure a rational organization and access to the necessary resources for survival: instrumental practices, norms, values, codes, formal and informal routines, styles of social association and bonding, spatial and temporal organization of different "milieus and ambiences"

\section{"Work in progress"}

Georges Friedmann é mais conhecido na França por suOur fundamental theoretical and methodological problems are oriented eminently towards propositions of a socioanthropological approach to communication processes. A social ecology that implies assuming a broad and non reductionist perspective of social - and collective - processes. The scope of research topics in communication is amplified towards the "interphases" and the problems dealing with strategic (re)production devices that reinforce the permanent reconstruction of social relations. We are replicating a theoretical framework of analysis that promotes the construction and refinement of propositions over different dimensions and categories associated to processes of (trans)formation of social collectives: in formal structured relations - mostly "institutionalized"-; in primary emotional bonds and informal relations (such as family, friends or "contention networks" for individuals in disadvantaged situations); productive activities (work); the "construction and distribution" of social regulated times and spaces; technological mediatization devices and processes (such as TIC's); and finally, research on the cultural and symbolic processes which accompany all interphases of social practices (in a double dimension: as a technical operative and informational level, and as a symbolic semiotic communicational process, Vizer 2008).

\section{Communication can be} considered the concrete and objective expression of the permanent process of reconstruction of the different "contexts of reality" we build and
cultivate in everyday life

a) We have tried to integrate in an inter(trans?) disciplinary conceptual framework different epistemological orientations and inputs from anthropology, social psychology, systems research, ecology, sociology and semiology. As it was said at the beginning, the aim was to develop research on complex and multidimensional interphase relations between social and different communication processes that can be associated with them.

b) We constructed propositions over different social categories and their relations to specific communication processes. We tested hypothesis over the "universality" of the proposed categories in different organizations and societies. These categories can be considered as "variables", subject to be operational through dimensions and indicators in empiric research over sociocultural practices.

c) We systematized the dimensions in a research device named as "Socioanalysis" (Vizer 2005, 2006, 2008). The application of the "Device" to different organizations and communities in different countries has allowed us to analyze sociocommunicational 
processes, diagnose problems and propose alternative lines of social intervention and action in institutions and communities.

d) Results have been highly positive, analyzing different social practices both "from and towards" a communicational approach. These results allow us to present here a synthetic set of problems related to different fields of communication research. We expect to find positive research propositions relating different socio-communicational dimensions to a) discursive processes, b) audiovisual mass media, c) technologies of information and communication (as in Internet for example).

\section{Dimensions and categories of analysis: beliefs, metaphors, and discursive constructions of reality}

As we said before, in relation to communication processes we can consider three different "functions or dimensions": referential, inter-referential and self-referential. We expect to enlighten sociocommunicational research processes and problems by "crossing" these dimensions with the social dimensions to be presented bellow.

Six "social" dimensions are being proposed. As said above, these dimensions can be considered as variables with specific indicators to be constructed in research (organizations and communities are studied as holistic and structured units of analysis, described and interpreted by a socioanalytical device, presented in other works and impossible to present here for lack of space, Vizer 2005, 2006, 2008). The social dimensions underlie a "ground" to communication and discursive processes that accompany them indissolubly. A strong hypothesis sustains that social dimensions, crossed - interphased, articulated - by the three communication ones, structure the ontological conditions for the processes of "meaning formation", both at the level of language and discourse as well as in any communication process (such as the mediatic processes). The combination of categories -or basic dimensions- organize different metaphorical orders of "the real, the symbolic, and the imaginary" in social life and in the formation of "universes of meaning" in culture and society (beliefs and myths over nature, society, the individual, culture and technology).

The dimensions (or categories) of analysis refer to a "topological construction" of "lifeworlds": the techné of instrumental practices and beliefs; the instituted and collective power organizations (such as Law and the State); appropriation of social times and spaces; social autonomous actions and emotional bonds in individual life; and to end with (last but not the least) culture and symbolic objects and devices as resources for the acknowledgement and (re)construction of environments by social agents (as actors).

Categories of socioorganizational analysis. Contributions to the construction and delimitation of research problems to discourse analysis, mass media and TIC's

1) Instrumental actions and practices, considered as "technologies" associated to production - and "ecological transformation" - of the perceived necessary resources for the functioning of a community, an organization (a system that has to achieve its goals). The life conditions and environmental relations, access to necessary resources and means of production, circulation and consumption. Obviously, production, economy, work and technology are of utter importance in this dimension.

a) Application to discourse analysis: rules of construction of discourse, as language could be analyzed in a separate level from operations that norm communication practices in everyday life.

b) Application to analysis of audiovisual media. Three instances can be separated:1) practices, operative devices and specific resources for production in each different media (cinema, TV., etc.). 2) Enunciation rules and devices of messages in each media and its physical supports. 3) Specific material conditions of reception.

c) "New" Technologies of Information and Communication (TIC's, Internet). Studies over social connectivity. Informational structure of technologies in organizational processes. Different - and compared - propositions about the role and influence of technology in conceptions of "Society of Information", of "communication", and Society of "Knowledge". Social and cognitive modifications in the applications and uses of TIC's.

2) Political organization. Collective dimension associated to the formal structures of institutionalized power in the form of Law and State. Legitimating of hierarchies, authority and rules of action and decision making, control of resources - both internal and external for organizations -. It corresponds to a paradigmatic structure of an organization - an "ecological" multilevel political order -, a system of social and legal domination that can be local, regional, national or extra-national (international organizations for example). Communication and discourse processes in this category could be analyzed as a "vertical vs horizontal" axis: constructing propositions over "equality vs inequality", "democratic vs authoritarian" practices in social relations and beliefs (the classic relations between State and society, division of powers, Law, mechanisms of control and legitimating, etc.)

a) Discourse analysis: "Official" formalized discourses. State institutions languages, "corporative language" (academic, legal, scientific languages, etc.). Institutionalized and performative discourse for reinforcement of institutional mechanisms of control.

b) Media analysis: media "power" devices, control and "effects". 1) Instances and conditioning of production and programming: norms and policies 
in medias; censorship. Propaganda and publicity. 2) content and ideological analysis; "Ideology" of mediatic production; social representations. 3) Instances of reception: restricted reception modalities and processes. "Conservative, critical or uncritical" reception attitudes.

c) TIC's:Studies over power vs participative relations, centralization or decentralization in networking and TIC's.

3) A dimension of "informal everyday life" practices and their symbolic and communication expressions (including antiestablishment organizations discourses, as opposed to the former category). Informal and spontaneous exercise of citizenship (in a horizontal perspective, as opposed to the former "vertical" one). For example: discourses of equality, rights to diversity (for individuals, groups, social and cultural sectors, gender, etc.). This "horizontal dimension" differences from the former radically, opposing itself to the structurally vertical, uneven and hierarchical visions and expressions of institutions, individuals and social agents, associated to differentiated access and possession of capital and power. The present dimension refers to alternative conceptions of democracy (as "direct or participative" democracy for instance) and relations between State and society, critics over hegemonic forms of exercising power in economical, political, class or party relations over citizens and society in general. It is a useful dimension for sociocommunicational analysis of radical and antiestablishment movements, human rights, minorities, gender, etc.

a) Discourse analysis: expressive and creativeperformative forms of language. Styles and uses in popular language. Language as social, symbolic and imaginary instatements. Democracy and discourse. Information and communication rights.

b) Media analysis: 1) production instance: freedom and creative forms of expression in media and arts; alternative media, communitarian, participative and popular communication. 2) Instance of mediatic products: content and ideological analysis. 3) Reception instance: (consuming) attitudes; passive or active; critical re-signifying and re-appropriation of massive and popular culture.

c) TIC's analysis. Research on social conditions for access and uses of TIC's: democratization, (de) concentration, participation in networks, political organizations and TIC's, social movements and collective action.

4) A specifically "topological and ecological" dimension of distribution and appropriation of spaces and time. Similarly to modern geographical research, social life is considered as both "physical and symbolic" in the structural and historic crossroads of multiple processes. The "administration" of time as a process that "cultivates, structures and organizes" different social spaces and territories, both private and public.

Communication research on paradigms of institutionalized adscription and distribution of practices over space and time in different contexts of public and private life. Appropriation of land and natural spaces being transformed into humanized symbolically referential cultural objects. For instance: beliefs and social representations of space and time related to specific practices in urban environments as cities, communities, organizations, public spaces and private homes; on rural activities; comparison between modern and traditional values and meanings over time and space; "civilized" vs "primitive" conceptions; new artificial and technologically constructed times and spaces (for instance in spaceship architecture) etc. The social and symbolic practices related to appropriation of time and space can create spatial representations and meanings of times past (narratives and representations of history), and a projection to the future, in which the present is both a real and an imaginary process continuously (re)presented as "making of history". The social construction of time and space can also be analyzed in different levels of reality: as physical, symbolic and communicational (as well as in imaginary representations).

a) Discourse analysis: uses of language and discourse to represent, describe or "construct" time and space as physical, symbolic and imaginary processes. Its uses and conceptions in the different (six) dimensions presented here.

b) Media analysis: construction of mediatic times and spaces. 1) instance of production: material and technological conditions and resources; rules and creativity in media production presentations. 2) Instance of media products: selection and combination of images and sounds that designate or connoted (imply) time, space and represented "scenarios" 3) Material-physical instances of reception: social and institutional (homes, schools, organizations, etc.). From spatial, social and temporal modalities of consumption/reception to imaginary and phenomenological representations of time and space in the reception process.

c) $\mathrm{TIC}^{\prime} \mathrm{s}$ analysis. Studies on construction and transformations of time and space in the implantation of TIC's.: connectivity, telematic and social networks.

"Ecological hypothesis": "We have a splendid example of the construction of time and space, comparing mass media technologies and devices which marked the XX century, with the "new" technologies of information and communication by the end of the century. For the first time in history, human technology was able to detain and freeze time, registering scenes, reproducing and diffusing them 
regardless space and time limitations, producing the effect of creating indefinitely subjective recreations of scenes in the imagination of viewers; thus, creating real "mediatic time and space". A new kind of symbolic and imaginary media topology, possible only because technology applied to media (or implied in media), creates an infinite spatial topology and the possibility of unending reproductions. In comparison, the new technologies (TIC's) can reverse time and space equation created by the first media revolution. TIC's can almost eliminate "natural" space, and replace it completely by virtual digital space. Construction of these new spaces in perception is a sub product of the new technological devices which allow us to appropriate ourselves of time: control it, cut it share it, stretch it or lengthen it. If the internal logic of media could only freeze and perpetuate Chaplin, Marilyn, Kennedy or Stalin, the revolutionary logic of $\mathrm{TIC}^{\prime} \mathrm{s}$ can realize the opposite operation: the "eternal", the spaces and representations exist in an indefinite flow of time. Control of time constitutes the independent variable of appropriation of both real and symbolic processes. Appropriation never fully realized, because the flowing never ends. In TIC's the unique "real appropriation" has become the virtual appropriation of reality.

5) A dimension of the subject and its associative and interpersonal bonds. We refer to an "emotional cultivation" environment, where humans can transform objects and other human beings in "objects of desire" (in a psychoanalitical perspective). In a bond, the subject is a subject to another, and therefore he recognizes himself as subject for himself. He acquires value and meaning in the eye of an Other, and that meaning and value is internalized, thus forming part of his own being. It is the eye of the observer that transforms me in an actor for him and for me, and it is the conscience of action (as actor and observer) which constructs me as an observer of an environment. It is fundamental to study both "instituted" forms and "institutionalizing" ones in the generation of social bondages, kindred, feeling of contention, community and protection networks.

a) Discourse analysis: use of language and discourse to represent, describe or to construct bonds and social relations as well as expressions of identity. Referentially and self-referentially in discourse (references to oneself and the other).

b) Media analysis: construction of characters and mediatic actors. 1) Production instance: construction of the "characters of the screen" (actors, speakers, presenters, stars, etc.). 2) Instance of media products: "primary emotions" and relations between the characters in drama and plots (in fiction or in news and information programs, propaganda and publicity) 3) Reception instance: representations, attitudes and identifications of receivers with the characters in the media (fiction or nonfictional).

c) TIC's analysis: transformations in social relations and intersubjective bonding. Formation of virtual networks with participative finalities: thematic nets, blogs, groups of contention, membership, personal searches of friends and affection.

6) Cultural, mythical and imaginary dimensions (religious manifestations included as transcendental projections). Narratives, ceremonies and rituals articulate an individual identity to collective "identifications", and certify a level of coherence or congruence between the "objective world" and the subjective perceptions. Traditionally, classic sociology attributes this dimension to the reproductive function of ideologies.

a) Discourse analysis: uses of language to express, represent, describe or construct "objects of culture". From an anthropological vision of material culture: arts and sciences.

b) Media analysis: 1) Production instance: values, norms, (re)creations and fusion of forms in culture 2) Product media instance; combination of images, sounds, plots and scenarios. Cultural representations. 3) Reception instance: uses and cultural consumptions. Physical, social and semiotic modalities of reception. Imaginary and phenomenological representations of characters in different scenes. Association with cultural images, myths, legends, symbols, etc.

c) TIC's analysis: cultural transformations and representations.

\section{Conclusion}

Communication sciences have been considered a paradigmatic example of inter(or trans)disciplinary studies. For some authors they have benefited -and for others they have suffered-from a hopeless indefinition and an epistemological ambiguity of their object studies, ranging from the omnipotent consideration that "everything is communication", down to its disqualification as a scientific field. To overcome this impasse and the fragmentation of the field, I consider that the construction of a sociocommunicational theoretical framework that would enable to share problematic and conceptual categories over interdependence between fundamental social practices and semiotic processes should be very fruitful. I intend to offer some theoretical strategies open to the construction of general propositions and hypothesis that could enable to orient some interdisciplinary (transdisciplinary ?) lines of research.

A modelization of shared social and communicational objects and strategies of research, would offer a mostly uncommon paradigm that could help to articulate different scope of problems - mostly separated between them by disciplinary, institutional 
and cultural boundaries - in order to allow a strategy of cooperative interdisciplinary (or bidisciplinary to start with) research in sociocommunicational and sociosymbolic processes and experiences, fundamental for the constitution (and the "ins-titution") of any kind of social life. And therefore, the development of the "social construction of lifeworlds" theory.

In any society, the six dimensions mentioned here can be considered different phenomenological kind of categorical experiences. Every one of them corresponds to a kind of specific category of "topology of real life". Any author can suggest adding or substracting dimensions, or even rejecting them, but the main point is that it proposes an "ecological and holistic" perspective on social life, both from the vision of objective practices and symbolic and semiotic meaningful/reflexive experiences. I believe it difficult to find other epistemological strategies to develop the proposition of meaningful social processes as the "construction" of them by active agents. History conditions humans, but humans "produce history" because they "believe" they can influence it, and because they attribute a purpose to their actions, as well as values and meanings.

Objectively the categories can be described and analyzed through indicators and patterns in a double perspective (corresponding approximately to the "double hermeneutic" theory proposed by Giddens and by "comprehensive" German sociology): as social objective facts, and as subjective processes in the construction of social life. They can be applied to institutions, social practices, discourses, and obviously to the production and reception processes in media, as well as in many social uses and applications of TIC's. Both, social processes and audiovisual products (films, or any kind of television programs) are fundamentally constructions of meaning that make reference to shared dimensions underlying "common sense" in every day life situations. They all share instrumental technical activities for material production and reproduction of life conditions (1). They all share the social pressure of power and collective institutionalized organizations (2). They also share the "resistance" to the former and alternative ways of modifying and transforming (many times through conflict) the "status $q u o^{\prime \prime}$ (3). They all need to appropriate and cultivate a "personal" time and space (public and private) in which the agents construct (cultivate) physically and symbolically their own "habitus" in a real world (4). They all recognize a constitutive social unity: as individuals, as family, group, clan, urban tribe, etc. All societies recognize some form of physical, emotional and symbolic bondages (5). And last, no "real life" context or media programs can be interpreted if cultural and semiotic dimensions are not shared and "projected" to a film, a program, a theatrical scene. Images and representations form a kind of "symbolic ecology" in which imagination, meanings and values can function as resources through which people construct their own "homeplace" in the world, their meaningful experiences, beliefs and identities (6). The interpretation of arts and media messages can be thought of as a phenomenological and "unconscious projection" of cognitive and emotional categories for the processing of meanings and values of every day life in order to interpret reflexively cultural products.

As mentioned before, agents constitute themselves (inter-referentiate and self-referentiate) through a double practice, the "double structuration" and the "double hermeneutics". So to investigate social processes we must consider practices in a double perspective: as "action" and as "meaning of an action", which can be analyzed as a communication process. Practices manifest themselves communicatively in three dimensions: a) as "referentiation" of objects of a real world (ontologically, a world manifested through the existence of "real" objects, whether symbolic or imaginary). B) as "inter-referentiation" and creation of real - and symbolic or imaginary (as in virtual reality) - contexts between social agents (not just "social interaction"). And c) as "self-referentiation" of the agents (the "personal" manners in which subjects present themselves and "construct" - consciously or not - their social personality and external images of themselves).

Finally, in reception processes of media, programs and messages are interpreted and "re-signified" selectively by heterogeneous publics precisely because they "obey" to certain common motivations and experiences that are fundamental to the constitution of the social world: topics related to power, conflict, survival, hate, love, ambition, some shared beliefs in values asfriendship, heroism, sacrifice, etc. Audiovisual media - and television in the first place since the second half of the 20th. century - have universalized spatially and culturally, a particular and hegemonic way to understand the "rules" of constitution of the social world by occidental perspectives, patterns and values. This process has been "internalized and legitimated" through techniques and production devices specifically developed by media industry (Hollywood in the first place). This can be recognized and acknowledged through the universal acceptance, the understanding and success of some films and television series during decades (for ex. "Gone with the wind", which completes now exactly 70 years).

So, to end with, we can work with the proposition that "social construction of reality" is more than just a dogma or a cliché, or an idealistic and obvious proposal impossible to test. Social reality "is", but in order to "be", humans must construct meanings to reality FAMECOS 


\section{NOTAS}

1 Lacan's categorization of three orders of "reality" is useful to our propositions. The "function" of the imaginary would consist in "filling up" with meaning, the empty spaces of the real and the symbolic.

\section{REFERÊNCIAS}

BOURDIEU, Pierre. Journalisme et éthique: actes du colloque fond. du centre de recherche de l'ecolesupérieure de journalisme. Les Cahiers du Journalisme, Lille, n. 1, jun. 1996.

BRAGA, José Luiz. Os estudos de interfase como espaço de construção do Campo da comunicação. Compós 2004. São Paulo: UMESP, 2004.

BERGER, Peter; LUCKMANN, Thomas. La construcción social de la realidad. Introducción. Amorrortu, Bs. As., 1986.

CHANG, Briankle. Deconstructing Communication. Univ. of Minnesota Press. Minne., 1996.

FOUCAULT, Michel; NIETZCHE, Friedrich; FREUD, Sigmund; MARX, Karl. Anagrama, Barcelona, 1970.

GIDDENS, Anthony et.al. La teoría social, hoy. Alianza, México, 1991.

LULL, James. Media, communication, culture, a global approach. Columbia Univ. Press, New York, 1995.

MORIN, Edgar. Introducción al Pensamiento complejo. Gedisa, Barcelona, 1996.

PAPPERT, Seymour; TURKLE, Sherry. Epistemology and Learning Group, Media Laboratory, Massachusetts Institute of Technology. Origin.1990.

PIAGET, Jean (comp.) Epistemología de las Ciencias humanas. Proteo, Bs. As. ,1972.

PRYGOGINE, Ilya. Time, Dinamics and Chaos. In: CHAOS: The New Science. XXVI Nobel Conference. Saint Peter, Minnesota, , 1993.

SFEZ, Lucien. Crítica de la Comunicación. Amorrortu. Bs. As, 1995.

TACUSSEL, Patrick. A sociologia interpretativa. Revista da Famecos No 18, agosto 2002. PUCRS, Brasil

TURKLE, Sherry; PAPERT Seymour. Epistemological Pluralism: styles and voices within the computer culture
VIZER. Eduardo Andrés. La trama (in)visible de la vida social: comunicación, sentido y realidad. Ed. La Crujía. Buenos Aires. 2003/06 (2ª .edición).

- Mediatizaçao e (trans)subjetividade na Cultura Tecnológica. A dupla face da sociedade mediatizada. In: Mediatizaçao e processos sociais na América Latina. Vários organizadores. Ed. Paulus, Sao Paulo, Brazil. 2008.

Procesos sociotécnicos y mediatización en la Cultura tecnológica. In: Sociedad Mediatizada. Denis de Moraes (org.). Ed. Gedisa, Barcelona, España 2007.

. Repensar la información y lo social e "impensar" la comunicación. In: Investigar em comunicación. Teorías y estrategias de intervención y socioanálisis. Ed. La Crujía, Buenos Aires (en prensa).

- Paradigmas y estilos de conocimiento: "cultivando dominios sociales", capít. de libro electrónico Nós trasdiciplinamos. Arm@zem digital (Brasil).

Socioanálisis, acción colectiva e intervención social estratégica. Savia, No. 5. Public. Dept. Trabajo Social. Universidad de Sonora, México 2008.

Socioanálisis: metodología de investigación, análisis diagnóstico e intervención social. Savia No. 5. Public. Dept. Trabajo Social. Universidad de Sonora, México 2008.

WALLERSTEIN, Imannuel; PRIGOGINE Ilya.; et.al. Open the Social Sciences, Report of the Gulbenkian Commission on the restructuring of the Social Sciences. Documento original, Lisboa, 1995. 